\title{
Optimal DTC Control Strategy of DFIG Using Variable Gain PI and Hysteresis Controllers Adjusted by PSO Algorithm
}

\author{
Mokhtar Amer ${ }^{1 *}$, Abdallah Miloudi ${ }^{1}$, Fatiha Lakdja² \\ 1 Geometry, Analysis, Control and Applications Laboratory, Department of Electrical Engineering, Faculty of Technology, \\ Dr Tahar Moulay University of Saida, P. O. B 138, 20000 Ennasr, Saida, Algeria \\ 2 Intelligent Control and Electrical Power System Laboratory, Department of Electrical Engineering, Faculty of Technology, \\ Dr Tahar Moulay University of Saida, P. O. B 138, 20000 Ennasr, Saida, Algeria \\ *Corresponding author, e-mail: mokht.amer@yahoo.fr
}

Received: 19 April 2019, Accepted: 23 June 2019, Published online: 30 October 2019

\begin{abstract}
This paper presents an optimal Direct Torque Control (DTC) strategy for Doubly Fed Induction Generator based wind turbine. The proposed strategy is considered based on Particle Swarm Optimization (PSO) Algorithm. The PSO is found to be robust and fast in solving nonlinear problems. Motivation for application of PSO approach is to overcome the limitation of the conventional controllers design, which cannot guarantee satisfactory control performance when designed by trial and error. In this work PSO algorithm was used to adjust the hysteresis torque and flux comparators bandwidths and to tune the parameters of Variable Gain PI (VGPI) controller designed for Maximum Power Point Tracking (MPPT) speed control of wind turbine to ensure high performance torque control. The optimal control strategy is considered in detail and it is shown that the use of the optimized controllers reduces rotor flux and electromagnetic torque ripples and improves the system dynamic performances. The effectiveness of the proposed direct torque control based on PSO algorithm (optimal DTC) method is illustrated through simulations on 1.5 MW DFIG based wind turbine. Simulation results illustrate the improved performances of optimal DTC compared with the conventional DTC.
\end{abstract}

Keywords

Doubly Fed Induction Generator, Direct Torque Control, hysteresis comparator, optimization, PSO algorithm, VGPI controller

\section{Introduction}

Fatal energy shortage and environmental pollution have led to more interest in renewable energy; one of the most attractive renewable energy sources for generating electrical power is wind energy. Exploitation of this endless energy is increasing rapidly worldwide [1]. Nowadays, the most widely used wind turbine generator is a Doubly Fed Induction Generator (DFIG) due to its variable speed operation, reactive power capability, and four-quadrant mode [2]. The Voltage Source Converter only needs to handle a fraction $(25 \%-30 \%)$ of the total power to achieve full control of the generator which means a low amount of power losses and reduced cost [1].

These advantages make them more interesting as compared to the Synchronous Generator (SG) based Wind Energy Conversion System (WECS). The behavior of the Voltage Source Converter and the associated wind turbine generator relies on the performance of its control system. With well-designed controllers, it is possible to increase power quality and improved dynamic performance. In recent studies, modern control techniques such as variable structure control, predictive control and intelligent control [3-6], have been intensively investigated for controlling the nonlinear components in power systems. However, these control techniques have few real applications due to their complicated structures.

Direct Torque Control (DTC) based on hysteresis comparators and conventional controllers (Proportional Integral PI, Variable Gain Proportional Integral VGPI), is still the most commonly used control technique in power systems. Unfortunately, even if the structures of the conventional controllers are simple, their tuning is tedious due to the nonlinearity and the complexity of the system.

In recent years, studies using Swarm Intelligence algorithms as a tool for tuning the controller's parameters have increased such as Particle Swarm Optimization (PSO), ant colony, artificial bee, differential evolution and genetics $[7,8]$. 
The advance in the use of Swarm Intelligence such as a PSO algorithm in engineering applications brings an opportunity for researchers to improve and advance in the design and optimization of systems [9].

In this paper, an optimal Direct Torque Control based DFIG wind turbine system is proposed. The hysteresis comparators bandwidths designed for torque and rotor flux control, and the parameters of the Variable Gain PI speed tracking controller used for Maximum Power Point Tracking (MPPT) are both adjusted applying the Particle Swarm Optimization (PSO) Algorithm. The aims of their optimization are to reduce the torque and rotor flux ripples for maximum wind power generation. PSO algorithm is preferred to optimize the gain parameters of controllers used in the proposed strategy since, when compared with the other swarm algorithms, its concept can easily be modeled on a computer and requires less computational memory $[7,8]$.

Firstly, conventional Direct Torque Control method of Doubly Fed Induction Generator is presented with speed tracking control based on PI controller for MPPT Wind Energy Conversion System, and then the PI controller is substituted by a VGPI controller. Using Particle Swarm Optimization (PSO) algorithm, VGPI parameters and hysteresis comparators bands are tuned for optimum wind power generation and improved dynamic performances.

\section{Wind Energy Conversion System modeling}

\subsection{Wind turbine model}

Power generated by the wind turbine is given by:

$$
P_{t}=\frac{1}{2} \rho A C_{p}(\lambda, \beta) v^{3} \text {. }
$$

Where $\rho$ is air density, $A$ is the area swept by the rotor blades, $v$ is the wind speed, $C_{p}$ is the coefficient of power conversion and $\beta$ is the blade pitch angle. The Tip Speed Ratio is given by:

$$
\lambda=\omega_{t} R / v
$$

Where $R$ and $\omega_{t}$ are the rotor radium and shaft speed, respectively [10]. The characteristic of $C_{p}(\lambda, \beta)$ can be approximated by nonlinear function:

$$
\begin{aligned}
& C_{p}(\lambda, \beta)=0.22\left(\frac{116}{\lambda_{i}}-0.4 \beta-5\right) e^{\left(-\frac{12.5}{\lambda_{i}}\right)} \\
& \lambda_{i}=\left(\frac{1}{\lambda+0.08}-\frac{0.035}{\beta^{3}+1}\right)^{-1} .
\end{aligned}
$$

By using Eq. (3), the 3D plot of $C_{p}$ versus $\lambda$ for different values of the angle $\beta$ is shown in Fig. 1. The aerodynamic torque of the wind turbine is given by:

$T_{t}=\frac{1}{2} \rho A C_{p}(\lambda, \beta) v^{3} \frac{1}{\omega_{t}}$.

The role of the gearbox $G$ is to transform the turbine speed to the generator speed, and the aerodynamic torque to the torque applied on the shaft of the generator according to the Eqs. (6), (7) [10]:

$T_{e}=\frac{T_{t}}{G}$

$\omega_{r}=G \omega_{t}$.

Where $\omega_{r}$ and $G$ are the rotor angular velocity and the gear ratio, respectively. The dynamic equation of the wind turbine is given:

$J \frac{d \omega_{r}}{d t}=\frac{T_{t}}{G}-T_{e}-f \omega_{r}$

\subsection{Doubly Fed Induction Generator model}

The DFIG model in the rotor reference frame is expressed as Eqs.(9)-(12) [5, 11]:

$v_{s}^{r}=R_{s} i_{s}^{r}+\frac{d \psi_{s}^{r}}{d t}+j \omega_{r} \psi_{s}^{r}$

$v_{r}^{r}=R_{r} i_{r}^{r}+\frac{d \psi_{r}^{r}}{d t}$

$\psi_{s}^{r}=L_{s} i_{s}^{r}+L_{m} i_{r}^{r}$

$\psi_{r}^{r}=L_{r} i_{r}^{r}+L_{m} i_{s}^{r}$.

Where $v_{s}^{r}$ and $v_{r}^{r}$ are the stator and rotor voltages, $i_{s}^{r}$ and $i_{r}^{r}$ are the stator and rotor currents, $\psi_{s}^{r}$ and $\psi_{r}^{r}$ are

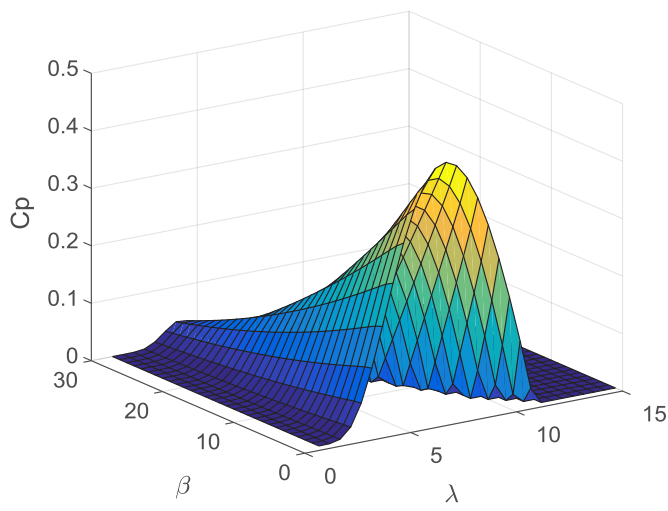

Fig. $13 \mathrm{D}$ plot of power coefficient $C_{p}(\lambda, \beta)$. 
the stator and rotor fluxes, $R_{s}, R_{r}, L_{s}, L_{r}$ and $L_{m}$ are the stator resistance, the rotor resistance, the stator inductance, the rotor inductance, and the mutual inductance, respectively. $\omega_{r}$ is the rotor speed. The electromagnetic torque developed by DFIG is expressed as Eq.(13) [11, 12]:

$T_{e}=\frac{3}{2} \frac{n_{p}}{2}\left(\psi_{\alpha r} i_{\beta r}-\psi_{\beta r} i_{\alpha r}\right)$.

Where $n_{p}$ is the number of pole pairs.

\subsection{Voltage Source Converter model}

The three phases and two level Voltage Source Converter (VSC) is used. The output voltage of VSC can be framed by Eq. (14) [12]. Where $V_{r a}, V_{r b}$ and $V_{r c}$ are the output voltage of VSC and $U_{d c}$ is the input DC voltage.

$\left[\begin{array}{l}V_{r a} \\ V_{r b} \\ V_{r c}\end{array}\right]=\frac{U_{d c}}{3}\left[\begin{array}{ccc}2 & -1 & -1 \\ -1 & 2 & -1 \\ -1 & -1 & 2\end{array}\right]\left[\begin{array}{l}S_{a} \\ S_{b} \\ S_{c}\end{array}\right]$

The converter output voltages in the rotor frame are given by Eqs. (15) and (16).

$$
\begin{aligned}
& v_{\alpha r}=\frac{1}{3} U_{d c}\left(2 S_{a}-S_{b}-S_{c}\right) \\
& v_{\beta r}=\frac{1}{\sqrt{3}} U_{d c}\left(S_{c}-S_{b}\right)
\end{aligned}
$$

\section{Control strategy}

\subsection{MPPT control}

Maximum Power Point Tracking (MPPT) algorithms are designed to search for the optimum operating point that allows the wind turbine to extract the maximum power from the available wind energy as shown in Fig. 2. Several MPPT control strategies have been proposed in the literature [13-16]. The MPPT employed in this study relies on the Tip Speed Ratio (TSR) control, which regulates

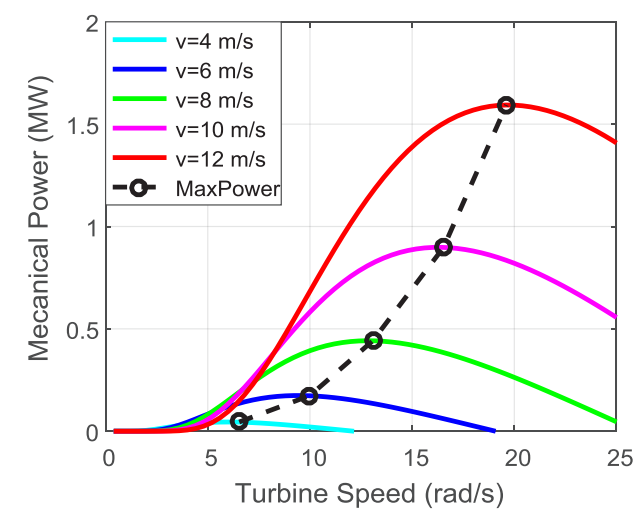

Fig. 2 The MPPT curve of 1.5 MW wind turbine the rotor speed, while keeping the TSR at its optimum value to capture the maximum wind power, at this value, $C_{p}(\lambda, \beta)$ is equal to its maximum value that is $C_{p \max }$ achieved for $\beta=0$ [13-17] according to Eq. (2):

$\omega_{\text {topt }}=\lambda_{\text {opt }} \frac{v}{R}$.

The optimum power from a wind turbine can be written as:

$P_{\max }=K_{o p t} \omega_{t o p t}^{3}$,

where

$K_{\text {opt }}=\frac{0.5 \rho \pi C_{p \max }\left(\lambda_{o p t}, \beta\right) R^{5}}{\lambda_{o p t}^{3}}$.

\subsubsection{PI controller for MPPT based TSR control}

The basic TSR control method regulates the rotor speed using a Proportional and Integral (PI) controller in order to maintain the Tip Speed Ratio $\lambda$ to an optimum value $\lambda_{\text {opt }}$ at which extracted power is maximum. From Fig. 3, the closed-loop transfer function of the system above is given by Eq. (20) [18]:

$f(s)=\frac{\left(K_{p} s+K_{i}\right)}{J s^{2}+\left(f+K_{p}\right) s+K_{i}}$.

$f(s)$ is a second order transfer function. It could be written by Eq. (21):

$f(s)=\frac{1}{J} \frac{\left(K_{p} s+K_{i}\right)}{s^{2}+\left(2 \zeta \omega_{n}\right) s+\omega_{n}{ }^{2}}$.

The expressions of the proportional and the integral gains could be gotten easily using the two previous equations; Eq. (20) and Eq. (21) [18]:

$\left\{\begin{array}{l}K_{p}=J 2 \zeta \omega_{n}-f \\ K_{i}=J \omega_{n}^{2}\end{array}\right.$.

\subsubsection{VGPI controller for MPPT based TSR control}

In this paper, the speed PI controller of MPPT based TSR control is replaced by a VGPI speed controller as illustrated in Fig. 4, to overcome a problem of overshoot during startup which is the most drawback of using a PI controller for speed tracking $[19,20]$.

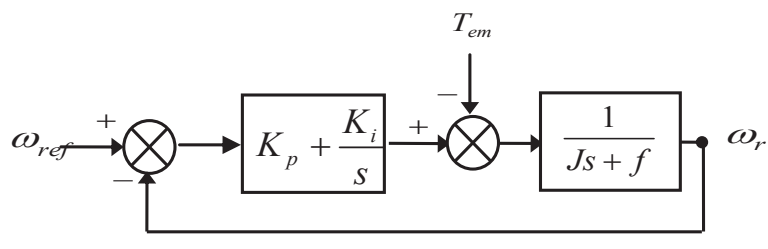

Fig. 3 The PI controller for MPPT based TSR control 


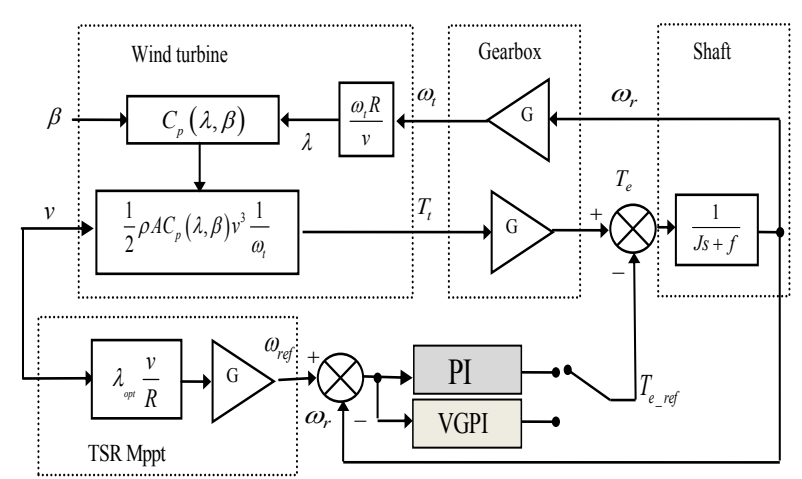

Fig. 4 The MPPT based TSR with speed tracking control [18]

The VGPI controller has the same structure of a classical PI controller with a variable proportional and integrator gains only along a controller's gain tuning polynomial curve with time [19].

The proposed controller has four tuning parameters:

- Initial gain value or startup setting which permits overshoot elimination.

- Final gain value or steady state mode setting.

- Gain transient mode function which is a polynomial curve.

- Saturation time which is the time at which the gain reaches its final value.

The degree $n$ of the gain transient mode polynomial function is defined as the degree of the VGPI controller. If $e(t)$ is the signal input to the VGPI controller then the output is given by Eq. (23) [20, 21]:

$y(t)=k_{p} e(t)+\int_{0}^{t} k_{i} e(t) d(t)$

with

$k_{p}=\left\{\begin{array}{cc}\left(k_{p f}-k_{p i}\right)\left(\frac{t}{t_{s}}\right)^{n}+k_{p i} & \text { if } t<t_{s} \\ k_{p f} & \text { if } t \geq t_{s}\end{array}\right.$

$k_{i}=\left\{\begin{array}{cc}k_{i f}\left(\frac{t}{t_{s}}\right)^{n} & \text { if } t<t_{s} \\ k_{i f} & \text { if } t \geq t_{s}\end{array}\right.$

Where $k_{p i}$ and $k_{p f}$ are respectively the initial value and the final value of the proportional gain and $k_{i f}$ the final value of the integrator gain of variable gain controller. $t_{s}$ is the saturation time and $n$ is the degree of the variable gain controller the initial value of $k_{i f}$ taken to be zero [21].

\subsection{Direct Torque Control of DFIG}

To control the electromagnetic torque in Direct Torque Control method used for DFIG it is necessary to control rotor flux vector magnitude and its angle which is measured in correspondence to stator flux vector in rotor frame $[19,23]$ :

$T_{e}=\frac{3}{2} n_{p} \frac{L_{m}}{\sigma L_{s} L_{r}}\left|\psi_{s}\right|\left|\psi_{r}\right| \sin \delta_{s r}$.

Where $\delta_{s r}$ is the angle between the rotor and the stator flux vector. Equation (26) shows that the torque depends on generator parameters, rotor, and stator fluxes magnitude and the angle between them. The rotor flux can be fully controlled via the Voltage Source Converter. By keeping the magnitude of rotor flux within a desired range, the electromagnetic torque becomes directly related to $\delta_{s r}$. Estimator block calculates torque, rotor flux and angle from the measured voltages and currents by the Eqs. (27)-(30) [12, 22, 23]:

$\psi_{\alpha r}=\int\left(v_{\alpha r}-R_{r} i_{\beta r}\right) d t$

$\psi_{\beta r}=\int\left(v_{\beta r}-R_{r} i_{\beta r}\right) d t$

$\left|\psi_{r}\right|=\sqrt{\left(\psi_{\alpha r}\right)^{2}+\left(\psi_{\beta r}\right)^{2}}$

$\theta_{r}=\tan ^{-1}\left(\frac{\psi_{\beta r}}{\psi_{\alpha r}}\right)$

The DTC system of DFIG consists of a rotor flux and torque estimator, a speed controller, a flux controller, a torque controller, and an optimum switching table (Table 1). Torque and flux references are compared with the actual values and a two-level for flux, and a three-level for torque hysteresis control method produces control signals [12, 22, 23].

\subsubsection{Flux and torque hysteresis comparators}

In DTC control, constant flux can be obtained by comparing the primary flux with the command flux. The output of the flux comparator will be Eq. (31) [22, 23]:

$$
\begin{array}{cl}
u \psi_{r}=1 & \text { if } \psi_{r}<\psi_{r}^{*} \\
u \psi_{r}=-1 & \text { if } \psi_{r}>\psi_{r}^{*}
\end{array}
$$

Table 1 Switching Table $(k=1,2, \ldots, 6$.) [11].

\begin{tabular}{ccccc}
\hline & \multicolumn{4}{c}{$u T_{e}$} \\
\hline & & 1 & 0 & -1 \\
$u \psi_{r}$ & 1 & $\mathrm{~V} k-1$ & $\mathrm{~V} 0,7$ & $\mathrm{~V} k+1$ \\
& -1 & $\mathrm{~V} k-2$ & $\mathrm{~V} 0,7$ & $\mathrm{~V} k+2$ \\
\hline
\end{tabular}




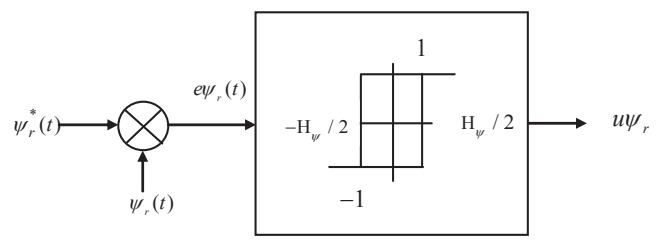

Fig. 5 Block diagram of two-level Hysteresis Band.

The output of the flux controller is a two levels hysteresis comparator as shown in Fig. 5. The DTC is acquired by sufficient selection between active and zero voltage vectors. Hence, when the torque $T_{e}$ is small compared with $T_{e}^{*}$ it is necessary to increase $T_{e}$ as fast as possible by applying the fastest vector. On the other hand, when $T_{e}$ reaches $T_{e}^{*}$ it is better to decrease $T_{e}$ as slowly as possible. Thus the output of the torque controller can be classified by Eq. (32):

$$
\begin{array}{ll}
u T_{e}=1 & \text { if } T_{e}<T_{e}^{*} \\
u T_{e}=0 & \text { if } T_{e}=T_{e}^{*} . \\
u T_{e}=-1 & \text { if } T_{e}>T_{e}^{*}
\end{array}
$$

The output of the torque controller is a three-level hysteresis comparator as shown in Fig. 6. The inverter output voltages are given by the outputs of the flux and torque comparators and the angle $\delta_{s r}$. Fig. 7 illustrates the conventional DTC control strategy for a DFIG based wind turbine [12, 22, 23].

\section{Proposed optimal DTC control strategy}

This paper presents an optimal Direct Torque Control allowing DFIG based wind turbine to extract maximum wind energy. In this study, the stator of DFIG is connected to the grid and the rotor is linked to the grid by a Voltage Source Converter. Generator speed, electromagnetic torque and rotor flux of DFIG are controlled by a combination of Variable Gain PI controller and hysteresis

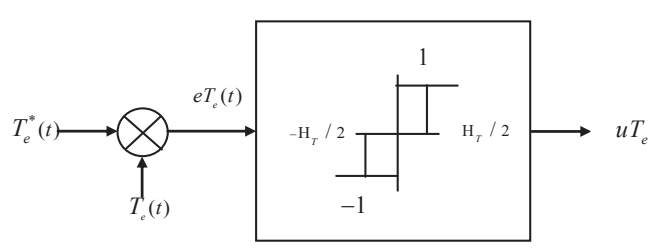

Fig. 6 Block diagram of three-level Hysteresis Band

comparators. Additionally, Particle Swarm Optimization (PSO) algorithm is adopted to improve the controller's performances by tuning VGPI and hysteresis comparators parameters. The effectiveness of the proposed DTC control is illustrated by the comparison with optimal and conventional methods. Generally, the hysteresis comparators bands and VGPI controller parameters are adjusted manually, which this method remains difficult and taken much time. In order to overcome this problem, we will employ in the present study the PSO algorithm for optimizing the VGPI controller parameters and the amplitude of hysteresis comparators. In the next section, the Particle Swarm Optimization algorithm was studied [24, 25].

\subsection{PSO algorithm research}

The Particle Swarm Algorithm is a Swarm Intelligence (SI) technique developed by Kennedy and Eberhart in 1995 [26]. PSO algorithm is inspired by the ability of flocks of birds and schools of fish to change their dispersion and regrouping direction in an unexpected synchronized way.

These behaviors are related to the search for solutions to nonlinear equations in a real search space giving origin to the technique of global optimization. In PSO, the positions of the particles that make up the swarm represent potential solutions to the optimization problem. The current position is represented by $x^{k}$ and is described by the

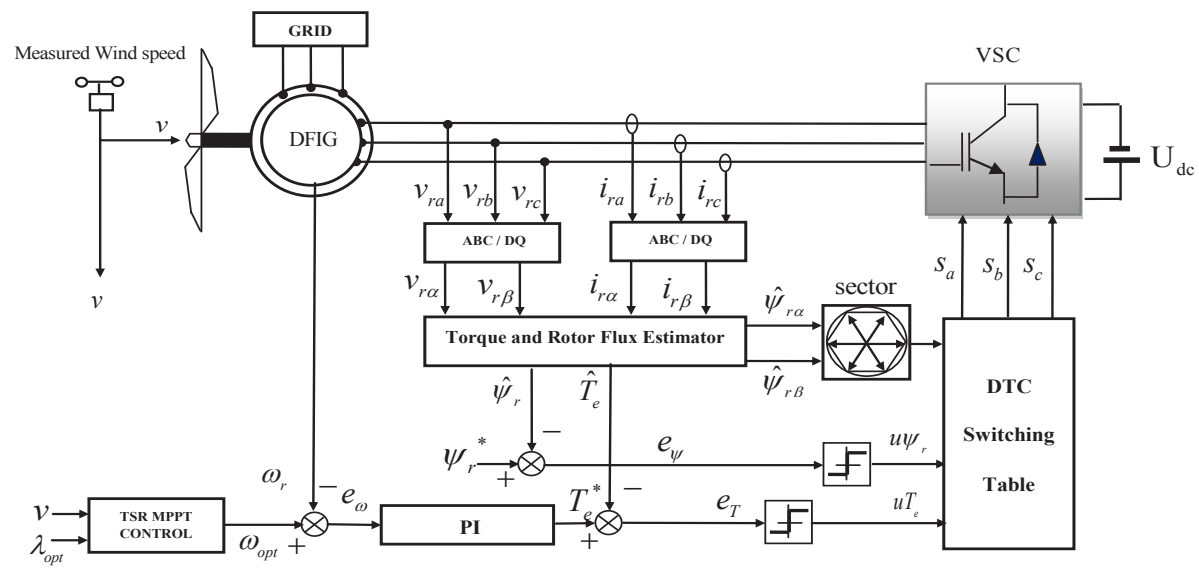

Fig. 7 Conventional DTC of DFIG based WECS scheme with PI Speed controller. 


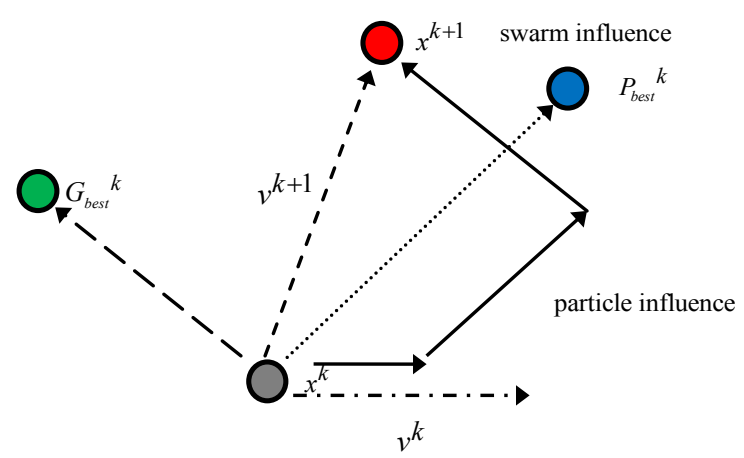

Fig. 8 The concept of a searching point by PSO [27].

velocity of the particle $v^{k}$ which can be represented by the concept of velocity as shown in Fig. 8 [27].

The velocity of each particle can be modified by Eq. (33):

$v^{k+1}=w v^{k}+c 1 r 1\left(P_{b e s t}-x^{k}\right)+c 2 r 2\left(G_{\text {best }}-x^{k}\right)$.

Using Eq. (33), a certain velocity, which progressively gets close to $P_{\text {best }}$ and $G_{b e s t}$ can be calculated. The current searching point can be modified by Eq. (34):

$x^{k+1}=x^{k}+v^{k+1}, \quad k=1,2,3, \ldots, n$.

Where $x^{k}$ is the current position, $x^{k+1}$ is a modified position, $v^{k}$ is current velocity, $v^{k+1}$ is modified velocity. $P_{\text {best }}$ is the best solution observed by current particle and $G_{\text {best }}$ is the best solution of all particles, $w$ is an inertia weight, $c 1$ and $c 2$ are two positive constants, and $r 1, r 2$ are the random number [28]. The following inertia weight is used by Eq. (35):

$$
w^{k}=w_{\max }-\left(\frac{w_{\max }-w_{\min }}{k_{\max }}\right) \times k .
$$

Where $k_{\max }, k$ are the maximum number of iterations and the current number of iterations, respectively. $w_{\min }$ and $w_{\max }$ are the minima and maximum weights respectively [28].

\subsection{VGPI controller and hysteresis comparators tuned by PSO algorithm}

In previous studies, the user has to adjust the value of parameters of the VGPI by the trial and error method to get a better response. The width of the torque and flux hysteresis band has often been chosen with a range of $(2.5 \% \div 4 \%)$ of their rated values. Unfortunately, the selection of these parameters manually is quite tedious. So the values of $k_{p i}, k_{p f}, k_{i f}, t_{s}$, $H_{T}$ and $H_{\psi}$ are found out by utilizing an optimization technique. Here, PSO algorithm is used to calculate the value of the parameter of the Variable Gain PI speed controller and to adjust the band of flux and torque hysteresis comparators which often have to be adjusted by trial and error method, so as to improve the performance of the controlled system. PSO is accurate and fast in the identification of controller's parameters because it converges faster compared to others metaheuristic algorithms [29, 30].

The flowchart of the optimal DTC control system based PSO algorithm is illustrated in Fig. 9.

\subsection{Construction of the fitness function}

The band amplitude of hysteresis comparators must be adjusted in such a way that torque and rotor flux ripples are reduced without increasing switching frequency and switching losses. Additionally, the parameters of VGPI controllers must be selected in such a way that overshoot and settling time of rotor speed are minimized and stability of the system is improved. To achieve this, a fitness function is formulated for the optimization process and consists of three terms on Integral Square Error (ISE) index [24]. The concept of optimal DTC is to minimize speed, torque, and rotor flux loops errors. Therefore, a fitness function is defined as:

$J=\int_{0}^{t}\left(k_{\omega} e_{\omega_{r}}^{2}(t)+k_{T} e_{T_{e}}^{2}(t)+k_{\psi} e_{\psi_{r}}^{2}(t)\right) d(t)$

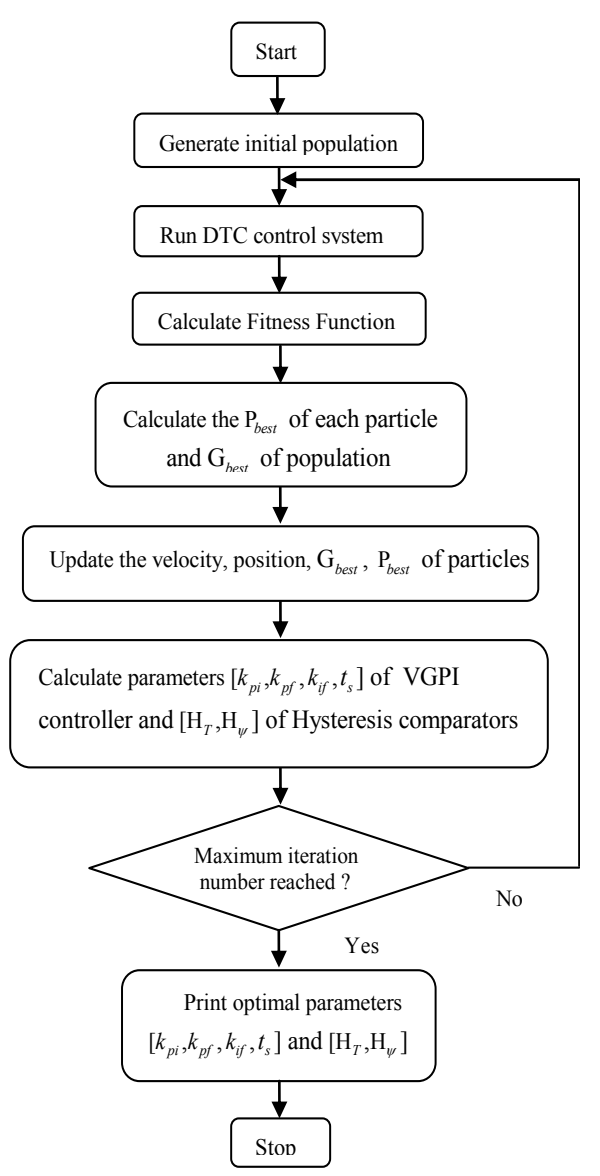

Fig. 9 The flowchart of the optimal DTC control system 


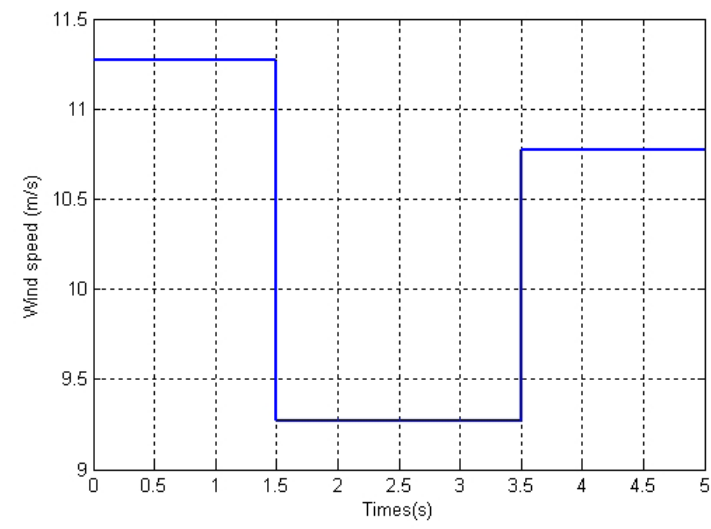

(a)

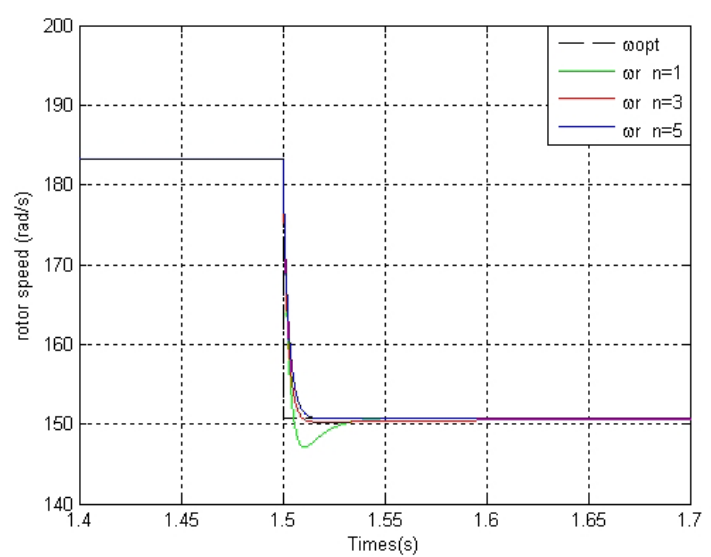

(c)

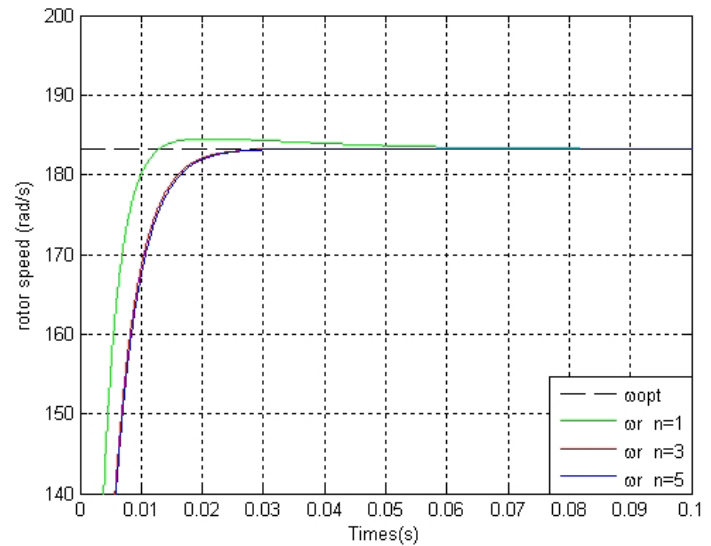

(b)

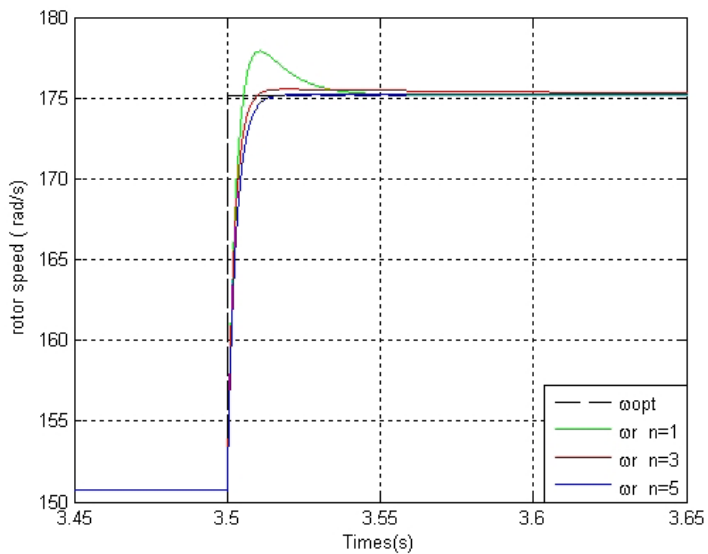

(d)

Fig. 10 (a) Wind profile (b) Overshoot at start comparison (c) Droop at step-down comparison (d) Overshoot at step-up comparison

Where $e_{\omega}(t), e_{T_{e}}(t)$ and $e_{\psi_{r}}(t)$ are rotor speed error, torque error and rotor flux error respectively. $k_{\omega}, k_{T}$ and $k_{\psi}$ are speed, torque and flux weighting factors.

\subsection{Optimization results}

Fig. 10 (a) shows the wind profile applied to the turbine. The resulting optimum values of the VGPI controller parameters and hysteresis bands of torque and flux comparators are summarized in Table 2. The optimization results are compared in Table 3 with various degrees of VGPI controller to choose the optimal value of $n$ which gives the best performance indices. Fig 10 (b), (c), (d) shows this comparison. Analysis of optimization results and performance indices show clearly that the optimum values are obtained with a VGPI controller which has $n=5$ as a degree. The values obtained with $n=5$ will be adopted for the optimal DTC strategy for comparison with the conventional DTC in the simulations as shown in Fig. 11.
Table 2 Optimization results

\begin{tabular}{lccc}
\hline & \multicolumn{2}{c}{ VGPI controller adjusted with PSO algorithm } \\
& $n=1$ & $n=3$ & $n=5$ \\
\hline$k_{i f}$ & $2.976 \mathrm{E} 5$ & $2.995 \mathrm{E} 5$ & $3.592 \mathrm{E} 5$ \\
$k_{p i}$ & $3.501 \mathrm{E} 5$ & $2.374 \mathrm{E} 5$ & $2.312 \mathrm{E} 5$ \\
$k_{p f}$ & $3.837 \mathrm{E} 5$ & $3.980 \mathrm{E} 5$ & $3.327 \mathrm{E} 5$ \\
$t_{s}(s)$ & 0.06814 & 0.4121 & 0.2911 \\
\hline & Hysteresis comparators adjusted with PSO algorithm \\
& $n=1$ & $n=3$ & $n=5$ \\
\hline$H_{T}$ & 184.1 & 172.1 & 166.8 \\
$H_{\psi}$ & 0.0023 & 0.0052 & 0.0048 \\
\hline
\end{tabular}

Table 3 Performances indices

\begin{tabular}{lccc}
\hline \multirow{2}{*}{ Performance indices } & \multicolumn{3}{c}{ VGPI Controller Degree } \\
& $n=1$ & $n=3$ & $n=5$ \\
\hline Overshoot at start \% & 0.6 & 0.00 & 0.00 \\
Overshoot at step-up \% & 1.54 & 0.17 & 0.00 \\
Droop at step-down \% & 2.45 & 0.13 & 0.00 \\
Settling time (s) & 0.075 & 0.030 & 0.027 \\
Torque RMSE & 219.8 & 46.96 & 45.28 \\
\hline
\end{tabular}




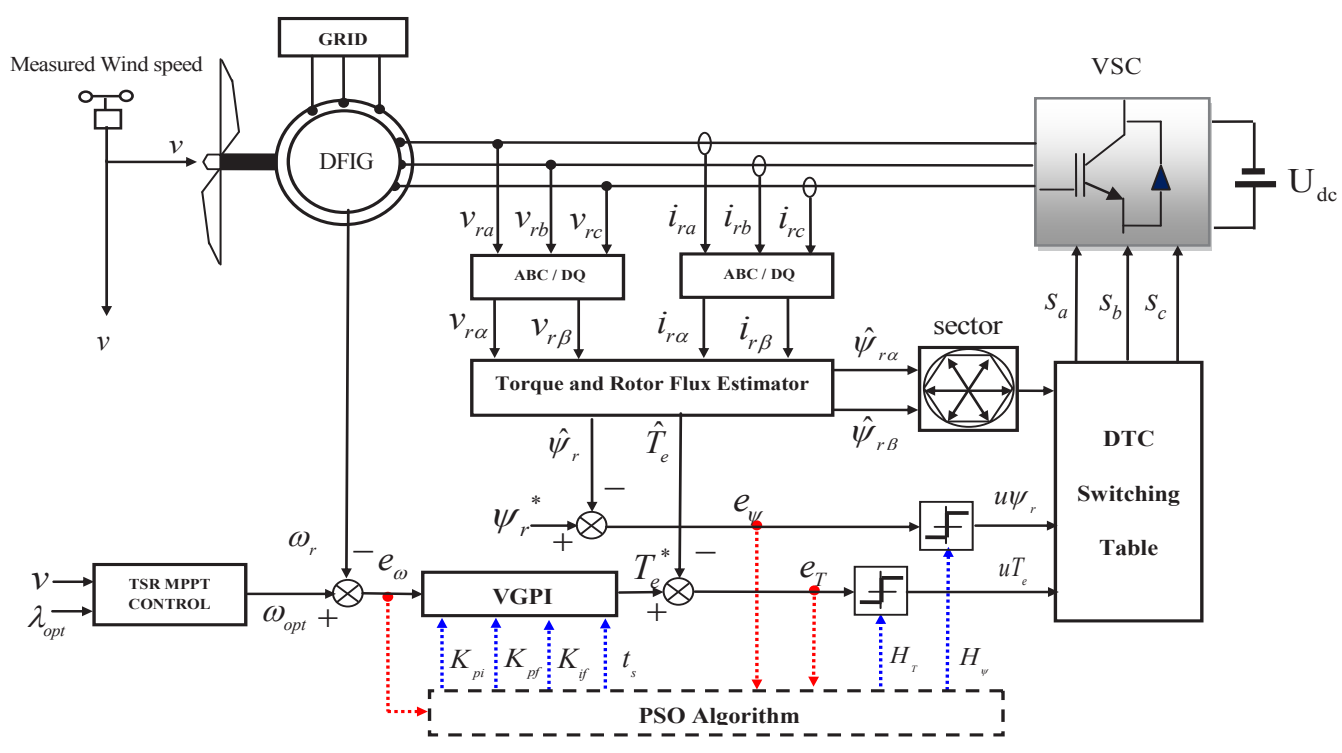

Fig. 11 Optimal DTC of DFIG based WECS scheme with VGPI Speed controller

To evaluate the performance of the optimized system Root Mean Square Error (RMSE) index is used as a performance criterion for electromagnetic torque error $e_{T}(t)$ :

RMSE $=\sqrt{\frac{\sum_{i=1}^{n} e_{T}(t)^{2}}{n} .}$

Torque ripples are reduced with lower the RMSE [24]. Performance indices are summarized in Table 3.

\section{Simulation results}

In this part, both Conventional DTC using PI speed controller and optimal DTC based VGPI controller, are simulated and compared regarding references tracking, rotor flux and torque ripples, rotor current harmonics distortion, and robustness against wind speed variations. Simulations are carried out with a $1.5 \mathrm{MW}$ DFIG machine connected to a $690 \mathrm{~V} / 50 \mathrm{~Hz}$ grid, using the Matlab software. Parameters of the wind turbine and the Doubly Fed Induction Generator are given in Appendix A and B [31]. Parameters of the PSO algorithm are given in Appendix C.

The wind turbine is subjected to a stepped wind speed profile as shown in Fig. 10 (a). The system is set to operate below-rated wind speed in which wind power optimization is sought. The determined value of the optimal Tip Speed Ratio $\lambda_{\text {opt }}$ is equal to 6.3 and the maximum power coefficient $C_{p \text { max }}$ is equal to 0.438 for the simulated wind turbine model. The referential rotor flux magnitude is set to $1.2 \mathrm{~Wb}$, and the referential torque is obtained from the MPPT control. The responses of torque, rotor flux, rotor speed and the rotor currents obtained with conventional DTC and optimal DTC control are compared.

\subsection{Rotor speed responses}

The system responses are observed for rated wind speed applied from start to $t=1.5 \mathrm{sec}$, and sudden decreasing in wind speed from $11.25 \mathrm{~m} / \mathrm{sec}$ to $9.25 \mathrm{~m} / \mathrm{sec}$ applied at time $t=1.5 \mathrm{se}$, then an impulsive wind speed to $10.75 \mathrm{~m} / \mathrm{sec}$ is applied at the time $t=3.5 \mathrm{sesec}$.

Fig. 12 (a) shows the responses of the optimal speed and the measured rotor angular velocity of the DFIG obtained for the two strategies. The angular reference speed of the rotor is obtained from the MPPT algorithm. It can be noted that the speed of the generator follows accurately the optimum speed in both methods.

Fig. 12 (b) shows that the rotor speed of conventional DTC presents a high overshoots at the start of the simulation. In the optimal DTC control, the optimized controller helps to achieve faster settling without overshoot. The waveform of the Tip Speed Ratio (TSR) at various wind speeds have been presented in Fig. 12 (c) and Fig. 12 (d). From these waveforms, it can be noticed that the values of the Tip Speed Ratio are kept in reference and the maximum value $\left(\lambda_{\text {opt }}=6.3\right)$ according to the operation of the MPPT algorithm.

Fig. 12 (d) shows that, when the wind speed varies suddenly, Tip Speed Ratio can fast reach around the optimal value. However, optimal DTC performs quicker wind speed variation disturbance rejection than the conventional DTC method. 


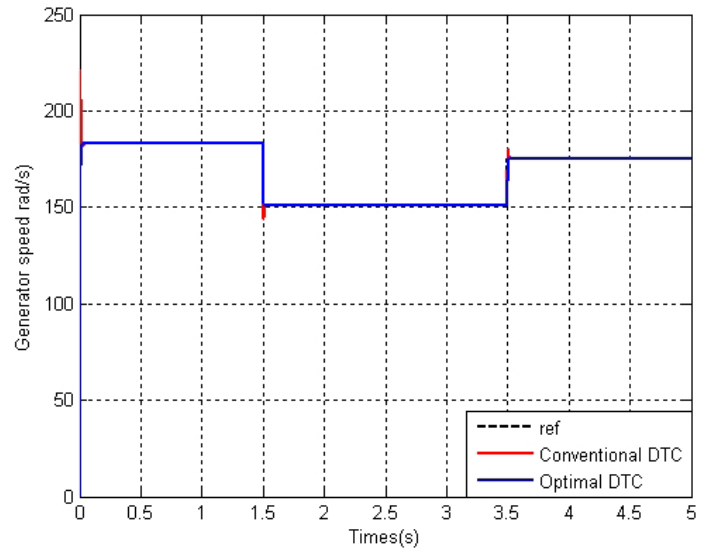

(a)

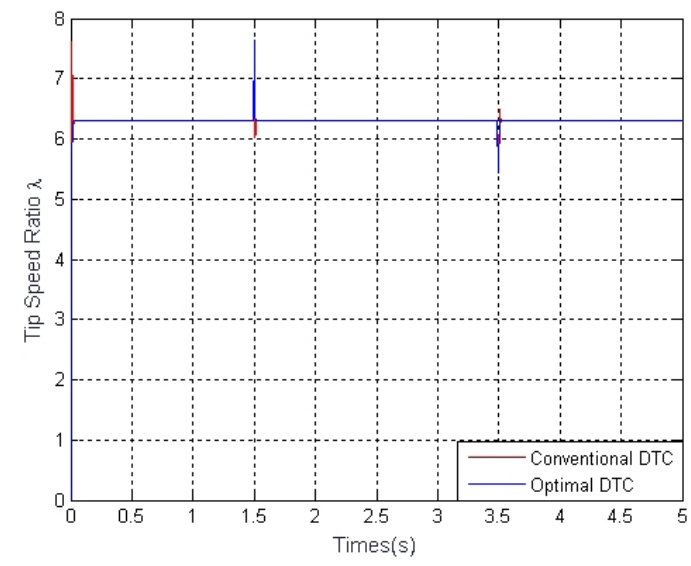

(c)

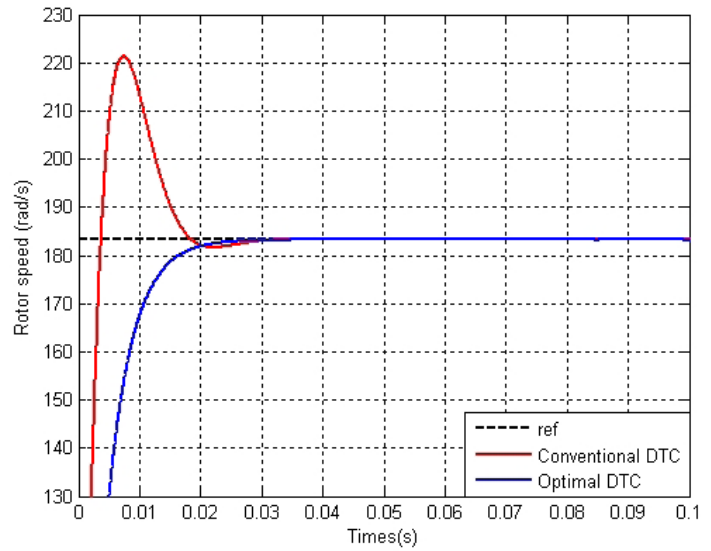

(b)

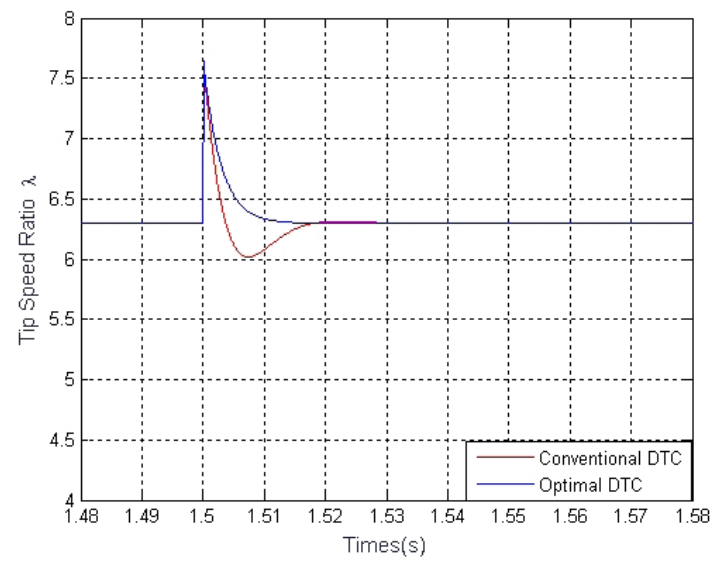

(d)

Fig. 12 (a) Rotor speed response comparison at start (b) Zoom of rotor speed response comparison at start (c) Tip Speed Ratio response comparison (d) TSR response at step-up wind speed

\subsection{Torque and rotor flux responses}

Fig. 13 (a) shows a comparison of the electromagnetic torque response produced by the DFIG controlled by conventional DTC and by optimal DTC. In Fig. 13 (b) we can observe that the electromagnetic torque follows its reference value very well but the ripples are not the same for both methods. On the other hand, we can notice the problem of a steady state error. It is clear that optimal DTC reduces torque ripples and corrects the steady state error.

The rotor flux magnitude response for both methods is shown in Fig. 13 (c) and (d). It can be stated that the rotor flux vector rotates with a constant magnitude and follow its reference value. From Fig. 13 (d), it's observed that the rotor flux trajectory of both methods is circular. The conventional DTC strategy represents high flux ripples and it is clearly seen that the optimal DTC provides fewer ripples and a better response.

\subsection{Rotor current responses}

Fig. 14 (a)-(d) shows the three-phase rotor currents drawn by Doubly Fed Induction Generator using conventional DTC and optimal DTC schemes. Fig. 14 (a) and (c) shows that the current contains fewer wave distortions in optimal DTC compared to conventional DTC. Fig. 14 (b) clearly depicts that the current drawn using DTC is not pure sinusoidal and contains wave distortions. Fig. 14 (d) shows in optimal DTC that the current drawn by DFIG is sinusoidal and contains fewer ripples compared to the DTC method. However in the starting transient region optimal DTC provides upper rotor currents than the conventional DTC method due to the random searching by PSO of optimum values at start of optimization and require short period of time to adjust the controller's parameters. 


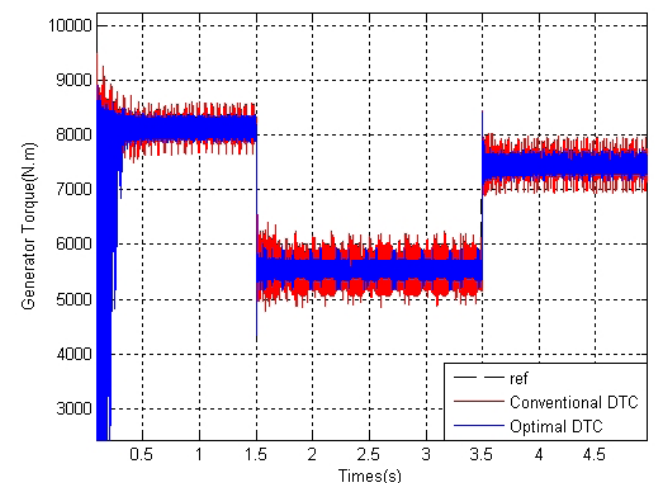

(a)

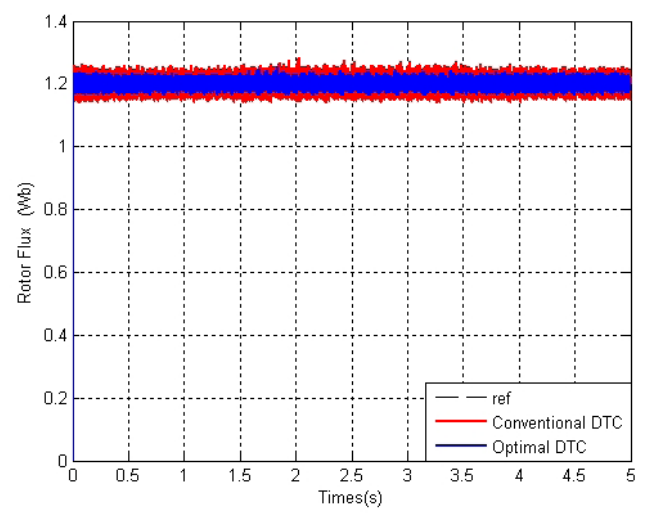

(c)

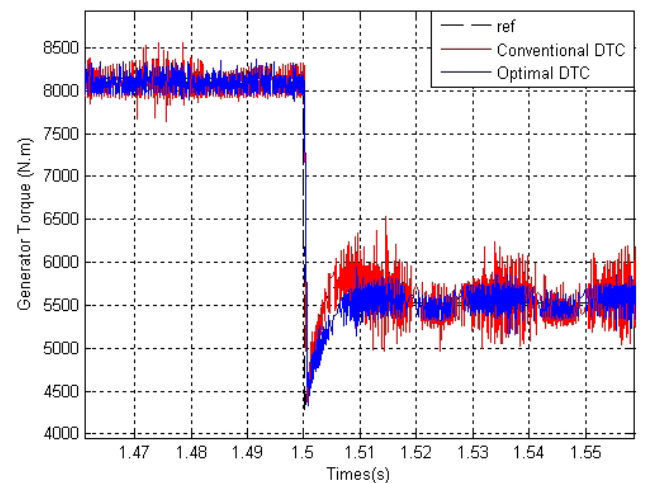

(b)

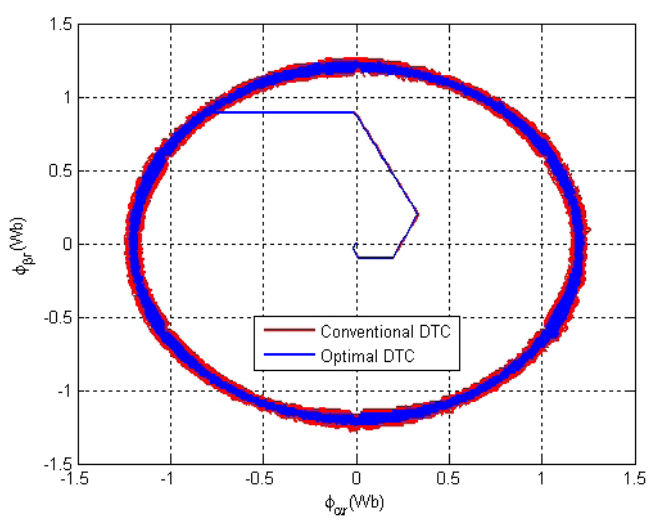

(d)

Fig. 13 (a) Torque response comparison (b) Zoom of torque response comparison (c) Rotor flux comparison (d) Rotor flux trajectory comparison

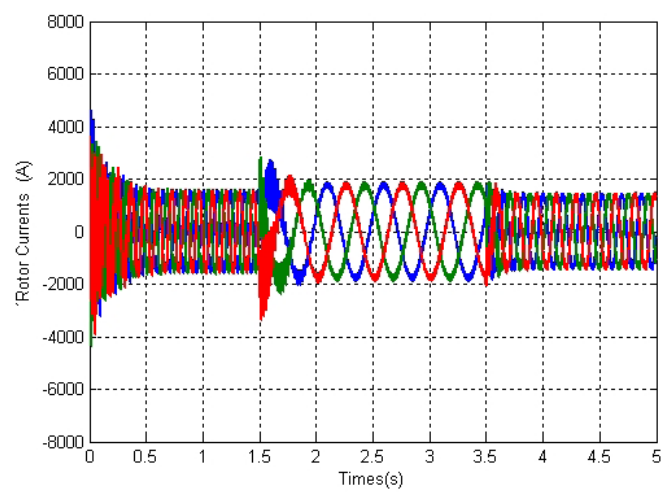

(a)

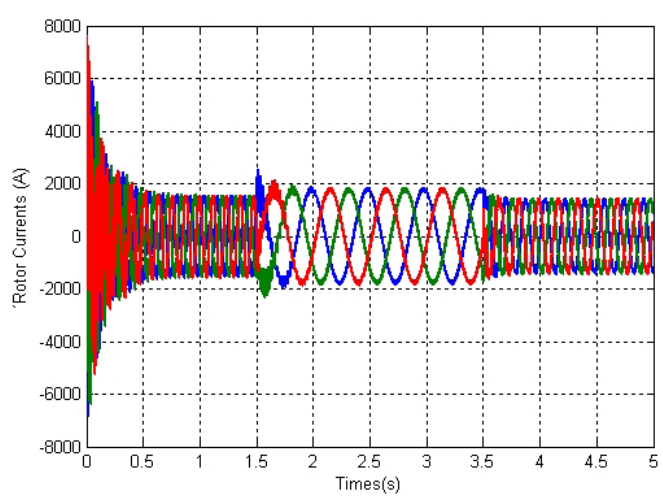

(c)

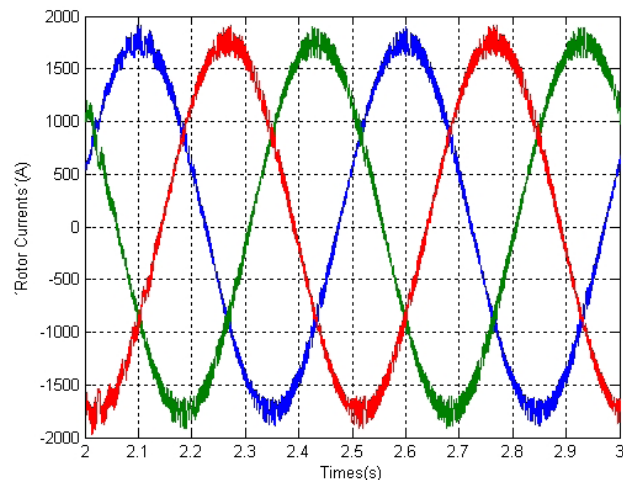

(b)

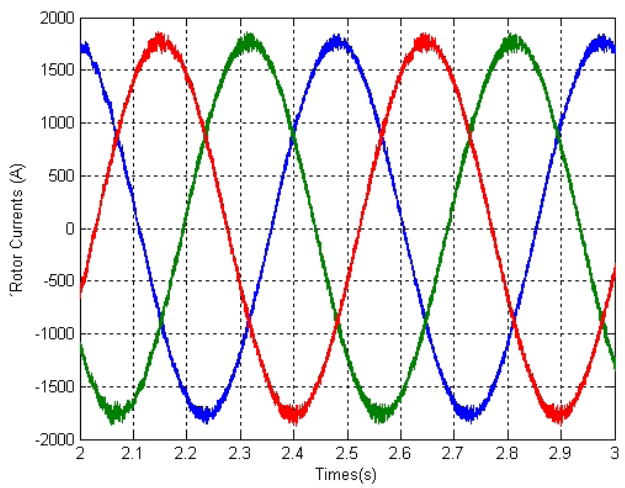

(d)

Fig. 14 (a) Rotor currents with conventional DTC (b) Zoom of Rotor currents with conventional DTC (c) Rotor currents with optimal DTC (d) Zoom of Rotor currents with optimal DTC 


\section{Conclusions}

In this present study, an optimal Direct Torque Control for a DFIG based wind turbine system was introduced in order to improve the generated wind turbine power. The controlling technique consists of a combination of Variable Gain PI controller and hysteresis comparators. This proposed approach was associated with PSO based evolutionary algorithm to optimize VGPI controller and hysteresis comparators in order to improve the control system performances. A comparison between proposed

\section{References}

[1] Qiao, W., Venayagamoorthy, G. K., Harley, R. G. "Design of Optimal PI Controllers for Doubly Fed Induction Generators Driven by Wind Turbines using Particle Swarm Optimization", In: IEEE International Joint Conference on Neural Network, Vancouver, BC, Canada, 2006, pp. 1982-1987. https://doi.org/10.1109/IJCNN.2006.246944

[2] Zarei, M. E., Nicolás, C. V., Arribas, J. R. "Improved Predictive Direct Power Control of Doubly Fed Induction Generator during Unbalanced Grid Voltage Based on Four Vectors", IEEE Journal of Emerging and Selected Topics in Power Electronics, 5(2), pp. 695-707, 2017.

https://doi.org/10.1109/JESTPE.2016.2611004

[3] Ebrahimkhani, S. "Robust fractional order sliding mode control of doubly fed induction generators (DFIG)-based wind turbines", ISA Transactions, 63, pp. 343-354, 2016.

https://doi.org/10.1016/j.isatra.2016.03.003

[4] Hu, J., Zhu, J., Zhang, Y., Ma, Q., Guo, Y. "Simple and Robust Predictive Direct Control of DFIG with Low Constant Switching Frequency and Reduced Torque and Flux Ripples", In: IEEE International Electric Machines \& Drive Conference (IEMDC), Niagara Falls, ON, Canada, 2011, pp. 771-776. https://oi.org/10.1109/IEMDC.2011.5994909

[5] Vayeghan, M. M., Davari, S. A. "Torque ripple reduction of DFIG by a new and robust predictive torque control method", IET Renewable Power Generation, 11(11), pp. 1345-1352, 2017. https://doi.org/10.1049/iet-rpg.2016.0695

[6] Douiri, M.R., Essadki, A., Cherkaoui, M. "Neural Networks for Stable Control of Nonlinear DFIG in Wind Power Systems", Procedia Computer Science, 127, pp. 454-463, 2018.

https://doi.org/10.1016/j.procs.2018.01.143

[7] Atacak, I., Küçük, B. "PSO-based PID Controller Design for an Energy Conversion System using Compressed Air", Tehnički vjesnik, 24(3), pp.671-679, 2017. https://doi.org/10.17559/TV-20150310170741

[8] Sahin, E., Ayas, M. S., Altas, I. H. "A PSO Optimized FractionalOrder PID Controller for a PV System with DC-DC Boost Converter", In: $16^{\text {th }}$ International Power Electronics and Motion Control Conference and Exposition, Antalya, Turkey, 2014, pp. 477-481.

https://doi.org/10.1109/EPEPEMC.2014.6980539 strategy (optimal DTC) and conventional DTC has been realized in the presence of wind variations. The profound assessment of the two methods is performed.

This study has shown that the use of the PSO Algorithm in tuning both the VGPI speed controller and the DTC comparators resulted in a limitation of the speed overshoot and a reduction of the torque and rotor flux ripples. The proposed approach provides then optimum wind power generation and improved dynamic performances compared to the conventional method.

[9] Greiner, D., Periaux, J., Quagliarella, D., Magalhaes-Mendes, J., Galván, B. "Evolutionary Algorithms and Metaheuristics: Applications in Engineering Design and Optimization", Mathematical Problems in Engineering, 2018, Article ID: 2793762, 2018. https://oi.org/10.1155/2018/2793762

[10] Fuchs, F., Mertens, A. "Dynamic Modelling of a 2 MW DFIG Wind Turbine for Converter Issues: Part 1", In: $15^{\text {th }}$ International Power Electronics and Motion Control Conference (EPE-PEMC), Novi Sad, Serbia, 2012, pp. DS2d.5-1-DS2d.5-7. https://doi.org/10.1109/EPEPEMC.2012.6397308

[11] Abad, G., López, J., Rodríguez, M. A., Marroyo, L., Iwanski, G. "Doubly Fed Induction Machine: Modeling and Control for Wind Energy Generation", IEEE Press Series on Power Engineering, John Wiley \& Sons, Inc., Hoboken, New Jersey, USA, 2011. https://doi.org/10.1002/9781118104965

[12] Wiam, A., Ali, H. "Direct torque control based power factor control of a DFIG", Energy Procedia, 162, pp. 296-305, 2019. https://doi.org/10.1016/j.egypro.2019.04.031

[13] Lei, Z., Sun, X., Xing, B., Hu, Y., Jin, G. "Active disturbance rejection based MPPT control for wind energy conversion system under uncertain wind velocity changes", Journal of Renewable and Sustainable Energy, 10(5), article ID: 053307, 2018. https://doi.org/10.1063/1.5037916

[14] Belabbas, B., Allaoui, T., Tadjine M., Denai. M. "High Order Sliding Mode Controller Simulation by a Wind Turbine for DFIG Protection against Overcurrent", Electrotehnica, Electronica, Automatica (EEA), 65(4), pp 142-147, 2017.

[15] Ananth, D. V. N., Nagesh Kumar, G. V. "Tip Speed Ratio Based MPPT Algorithm and Improved Field Oriented Control for Extracting Optimal Real Power and Independent Reactive Power Control for Grid-Connected Doubly Fed Induction Generator", International Journal of Electrical and Computer Engineering, 6(3), pp. 1319-1331, 2016. https://doi.org/10.11591/ijece.v6i3.9306

[16] Song, D., Yang, J., Su, M., Liu, A., Liu, Y., Joo, Y. H. "A Comparison Study between Two MPPT Control Methods for a Large VariableSpeed Wind Turbine under Different Wind Speed Characteristics", Energies, 10(5), article ID: 613, 2017. https://doi.org/10.3390/en10050613 
[17] Thongam, J. S., Ouhrouche, M. "MPPT Control Methods in Wind Energy Conversion Systems", In: Carriveau, R. (ed.)Fundamental and Advanced Topics in Wind Power, InTech, Rijeka, Croatia, 2011, pp. 339-360.

https://doi.org/10.5772/21657

[18] Ayrir, W., Ourahou, M., El Hassouni, B., Haddi A. "Direct torque control improvement of a variable speed DFIG based on a fuzzy inference system", Mathematics and Computers in Simulation, 2018. https://doi.org/10.1016/j.matcom.2018.05.014

[19] Miloudi, A., Draou, A. "Variable gain PI controller design for speed control and rotor resistance estimation of an indirect vector controlled induction machine drive", In: IEEE $28^{\text {th }}$ Annual Conference of the Industrial Electronics Society (IECON 02), vol. 1, Sevilla, Spain, 2002, pp. 323-328. https://doi.org/10.1109/IECON.2002.1187529

[20] Miloudi, A., Alradadi, E. A., Draou, A. "A New Control Strategy of Direct Torque Fuzzy Control of a PWM Inverter Fed Induction Motor Drive", In: IEEE International Symposium on Industrial Electronics, vol. 3, Montreal, Quebec, Canada, 2006, pp. 2535-2540. https://doi.org/10.1109/ISIE.2006.295971

[21] Draou, A., Miloudi, A. "A simplified speed controller for direct torque neuro-fuzzy controlled induction machine drive based on a variable gain PI controller", In: $4^{\text {th }}$ International Power Engineering and Optimization Conference (PEOCO), Shah Alam, Malaysia, 2010, pp. 533-538. https://doi.org/10.1109/PEOCO.2010.5559235

[22] El Ouanjli, N., Motahhir, S., Derouich, A., ElGhzizal, A., Chebabhi, A., Taoussi, M. "Improved DTC strategy of doubly fed induction motor using fuzzy logic controller", Energy Reports, 5, pp. 271-279, 2019. https://doi.org/10.1016/j.egyr.2019.02.001

[23] El-Kholy, E. E., Kalas, A., Fauzy, M., Dessouki, M. E., El-Refay M., El-Zefery, M. "High-Performance Direct Torque Control for Induction Motor Drive Fed from Photovoltaic System", International Journal of Energy and Power Engineering, 9(11), pp. 1285-1294, 2015.
[24] Laina, R., Lamzouri, F. E.-Z., Boufounas, E.-M., El Amrani, A., Boumhidi, I. "Intelligent control of a DFIG wind turbine using a PSO evolutionary algorithm", Procedia Computer Science, 127, pp. 471-480, 2018.

https://doi.org/10.1016/j.procs.2018.01.145

[25] Costa, B. L. G., Graciola, C. L., Angélico, B. A., Goedtel, A., Castoldi, M. F. "Metaheuristics Optimization Applied to PI Controllers Tuning of a DTC SVM Drive for Three-Phase Induction Motors", Applied Soft Computing, 62, pp. 776-788, 2018. https://doi.org/10.1016/j.asoc.2017.09.007

[26] Eberhart, R. C., Kennedy, J. "A new optimizer using particle swarm theory", In: Sixth International Symposium on Micro Machine and Human Science, Nagoya, Japan, 1995, pp. 39-43. https://doi.org/10.1109/MHS.1995.494215

[27] Boukhalfa, G., Belkacem, S., Chikhi, A., Benaggoune, S. "Direct torque control of dual star induction motor using a fuzzy-PSO hybrid approach", Applied Computing and Informatics, 2018. https://doi.org/10.1016/j.aci.2018.09.001

[28] Xiao, Y. "Research on SVG DC-Side Voltage Control Based-on PSO Algorithm", International Journal of Information Technology and Computer Science, 8(10), pp. 29-38, 2016. https://doi.org/10.5815/ijitcs.2016.10.04

[29] Thangavelusamy, D., Ponnusamy, L. "Comparison of PI controller tuning using GA and PSO for a Multivariable Experimental Four Tank System", International Journal of Engineering and Technology (IJET), 5(6), pp. 4660-4671, 2013.

[30] Jones, K. O., Bouffet, A. "Comparison of bees algorithm, ant colony optimisation and particle swarm optimisation for PID controller tuning", In: $9^{\text {th }}$ International Conference on Computer Systems and Technologies and Workshop for PhD Students in Computing (CompSysTech '08), Gabrovo, Bulgaria 2008, article ID: 29. https://doi.org/10.1145/1500879.1500912

[31] Wu, B., Lang, Y., Zargari, N., Kouro, S. "Power Conversion and Control of Wind Energy Systems", IEEE Press Series on Power Engineering, John Wiley \& Sons, Inc., Hoboken, New Jersey, USA, 2011. https://doi.org/10.1002/9781118029008

\section{Appendix}

\begin{tabular}{lcc}
\multicolumn{3}{c}{ Appendix A Wind Turbine Parameters } \\
\hline Rated Mechanical Power & $P m$ & $1.5 \mathrm{MW}$ \\
\hline Turbine Radius & $R$ & $35.25 \mathrm{~m}$ \\
Turbine inertia & $J t$ & $4.45 \times 10^{5} \mathrm{~kg} \mathrm{~m}^{2}$ \\
Number of Blades & & 3 \\
Optimum TSR & $\lambda_{\text {opt }}$ & 6.3 \\
Power Coefficient & $C_{p \max }$ & 0.4382 \\
Rated wind speed & $v$ & $11.27(\mathrm{~m} / \mathrm{s})$ \\
Gear Box & $G$ & 91 \\
\hline
\end{tabular}


Appendix B DFIG Parameters [31]

\begin{tabular}{|c|c|c|}
\hline Rated motor power & $P n$ & $1.5 \mathrm{MW}$ \\
\hline Rated stator voltage & $U s$ & $690 \mathrm{~V}$ \\
\hline $\begin{array}{l}\text { Nominal Rotor Speed } \\
\text { Range }\end{array}$ & $n r$ & $1200-1750 \mathrm{rpm}$ \\
\hline Rated Mechanical Torque & $\operatorname{Tn}$ & $8150 \mathrm{kN} \mathrm{m}$ \\
\hline Stator resistance & $R s$ & $2.65 \mathrm{~m} \Omega$ \\
\hline Rotor resistance & $R r$ & $2.63 \mathrm{~m} \Omega$ \\
\hline Stator inductance & $L s$ & $5.60 \mathrm{mH}$ \\
\hline Rotor inductance & $L r$ & $5.60 \mathrm{mH}$ \\
\hline Mutual inductance & Lm & $5.48 \mathrm{mH}$ \\
\hline Number of pole pairs & $n p$ & 2 \\
\hline Generator inertia & $J g$ & $890 \mathrm{~kg} \mathrm{~m}^{2}$ \\
\hline Viscosity & $f g$ & $0.0024 \mathrm{~N} \mathrm{~m} \mathrm{~s}^{-1}$ \\
\hline DC-bus voltage & $U_{d c}$ & $930 \mathrm{~V}$ \\
\hline \multicolumn{3}{|c|}{ Appendix C PSO Algorithm Parameters } \\
\hline Swarm Size & $P$ & 50 \\
\hline Max Iteration & $K_{\max }$ & 30 \\
\hline Constant 1 & $c 1$ & 2 \\
\hline Constant 2 & $c 2$ & 2 \\
\hline Minimum Weight & $w_{\min }$ & 0.4 \\
\hline Maximum Weight & $w_{\max }$ & 0.9 \\
\hline
\end{tabular}

